Sébastien Bertrand ${ }^{1}$, A. Burnett ${ }^{2}$, K. Saunders ${ }^{3}$, J. Striberger ${ }^{4}$, Y. Axford ${ }^{5}$ and S. Coulter ${ }^{6}$ (Workshop Participants)

'Woods Hole Oceanographic Institution, USA; sbertrand@whoi.edu

¿University of Minnesota, Minneapolis, USA; ${ }^{3}$ University of Tasmania, Hobart, Australia; ${ }^{4}$ Lund University, Sweden; ${ }^{5}$ University of Colorado, Boulder, USA; ${ }^{6}$ Queen's University Belfast, UK

Earth scientists are increasingly using natural archives to reconstruct past changes in climate, seismic activity, ocean circulation, glacial advances, atmospheric composition, etc. In order to compare geological records across space and time, they need to be properly dated and accurate chronologies need to be developed. Although several dating techniques have been in use for the last 50 years, the methods are still evolving and being refined.

To familiarize geoscientists with recent developments in dating techniques, the European Science Foundation sponsored a EuroCLIMATE Spring School on "Late Quaternary Timescales and Chronology" from 20 to 26 April 2008, in Piran, Slovenia. The Spring School, organized by Barbara Wohlfarth (Stockholm University, Sweden) and Bernd Kromer (University of Heidelberg, Germany) brought together 15 lecturers and 40 participants from 17 different countries, mainly from Europe but also Australia, New Zealand and the USA. The meeting included topical lectures, short participant presentations, and poster and discussion sessions. During the week, participants received various important insights regarding the development of accurate chronologies for their records. The most important issues discussed during the meeting are summarized hereafter.

First, every method requires appropriate samples. Selecting suitable samples may be tricky, especially for optically-stimulated luminescence (OSL) and cosmogenic radionuclide dating, and it is advisable to work in close collaboration with the lab running the samples. It is also essential to select appropriate dating techniques, apply them consistently, and clearly indicate the precision, methodological details and assumptions of the selected techniques in publications. For the radiocarbon technique, for example, authors should always clearly indicate the nature of the analyzed samples (e.g., bulk sediment vs macrofossil). Moreover, as numerous calibration and correction datasets have been published since the discovery of the radiocarbon dating technique, scientists should be extremely careful to select appropriate datasets for calibration and correction of radio-

carbon results. Again, these choices should

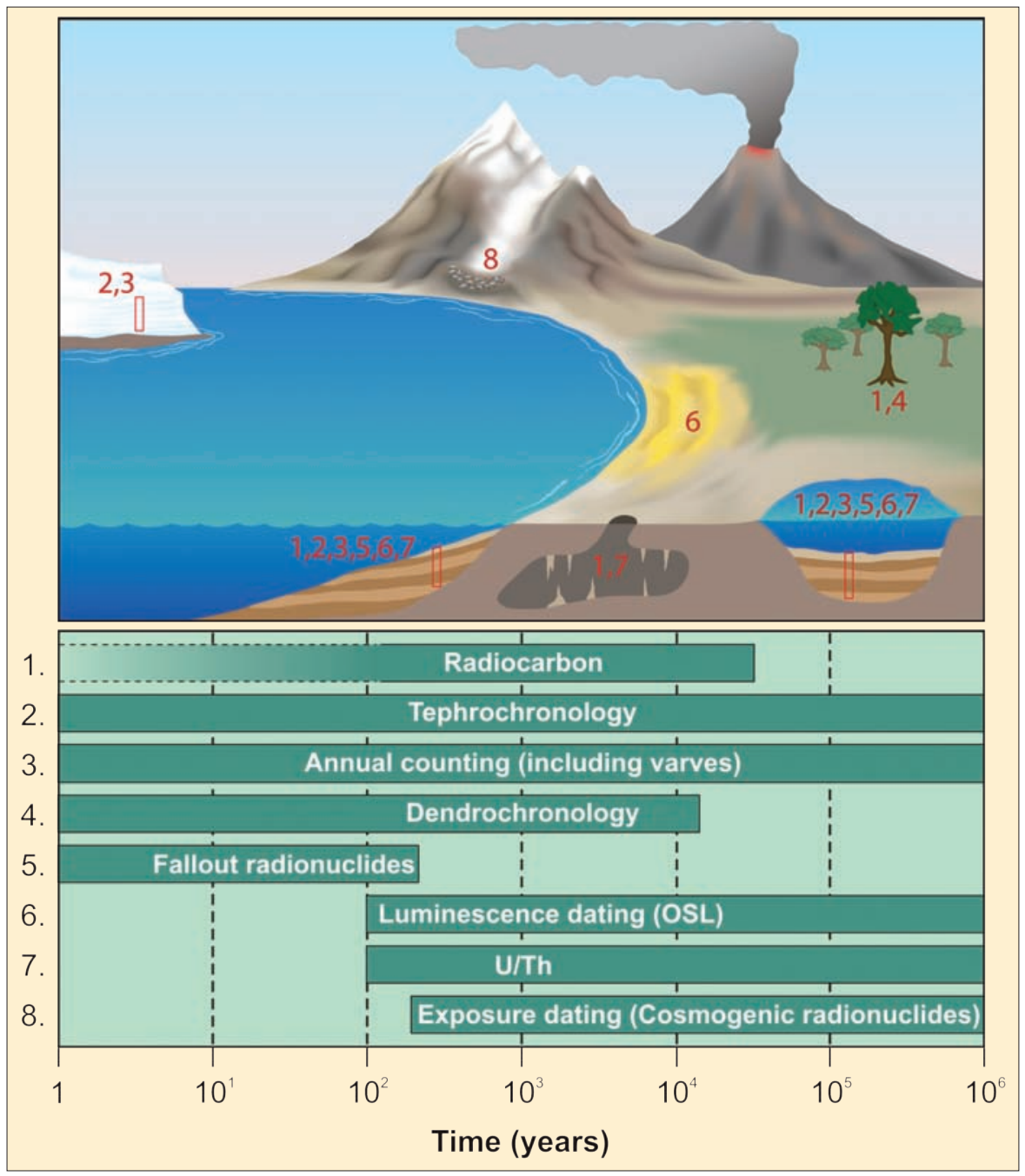

Figure 1: Late Quaternary depositional environments (ice caps, glacial moraine deposits, loess and sand dunes, trees, marine sediments, speleothems, lake sediments) and associated dating techniques discussed during the ESF Spring School. The lower part of the figure represents the effective dating ranges of the different techniques.

be clearly stated in the resulting publications. Several free software programs are available for download (BCal, Bpeat, OxCal, Calib), and they all feature the most common calibration and correction options.

Second, it is common practice in geosciences to apply a linear age model between dates or to use a polynomial regression to model an age-depth relationship. Martin Blaauw, in particular, illustrated the fallacy in this approach. It is essential when constructing age models to consider prior knowledge of the archive, including visible sedimentological changes, hiatuses, density changes, etc.-all of which are likely to be associated with a change in sedimentation rate. A variety of tools based on Bayesian statistics (e.g., OxCal 4.0) are now available to help construct these models and should always be used when constructing chronologies.

Third, attendees discussed the rationale and best practices to tune and wigglematch paleo-records. As the lead and lag relationship between paleoclimate events is an important issue in recent paleoclimate research, extreme care must be taken before tuning or wiggle-matching records. A distinction was made between the two terms, which are often used inappropriately. Tuning is changing the chronology of a record to match a known cyclicity, based on a known cause-and-effect relationship (e.g., orbital tuning). Wiggle-matching is matching events without a known mechanistic link and/or cyclicity. The main conclusion reached among the attendees was that a simple correlation without a cause- 
and-effect explanation is not sufficient to tune or wiggle-match records. Scientists should first use independent chronologies to demonstrate that the records behave synchronously and there must be reason to believe the records are driven by the same mechanisms. Once such a comparison has been made, it is then permissible to tune or wiggle-match. It is recommended to use a reasonable number of tie-points but not more than two per distinct lithological unit, as too many tie-points would cause unnatural breaks in accumulation rates.

This Spring School was a great opportunity for senior and younger scientists to meet and discuss different chronological issues. The 17 lectures and the 40 participant presentations covered a wide range of dating techniques available for Late Quaternary archives, as well as various geographic areas. It is hoped that participants will use and circulate the information regarding best practices for constructing Late Quaternary chronologies-from sample selection in the field to publication of the results.

\section{A new PAGES Working Group: Arctic2k - Arctic climate during the last 2 millennia}

\section{Boulder, USA, 8 March 2008}

\section{Nalan Koç}

Norwegian Polar Institute,Tromsø; nalan.koc@npolar.no

Climate change in the Arctic is amplified, mostly due to ice- and snow-albedo feedback effects. Warming in the Arctic has occurred at about twice the rate of the global mean, both from the $19^{\text {th }}$ to $21^{\text {st }}$ centuries and from the late 1960 s to present (Arctic Climate Impact Assessment, 2004). This trend has further accelerated during the past decade, as evidenced both by the dramatic decrease of summer sea ice cover and increased melt rates of glaciers (e.g., Kohler et al., 2007; Comiso et al., 2008). Observed increases in Arctic river discharge and freshening of Arctic water masses are consistent with human-induced Arctic moistening (Min et al., 2008). The effects of anthropogenic warming will continue to be superimposed on natural climate variability. Unfortunately, Arctic instrumental measurements only extend back to the mid-20 $0^{\text {th }}$ century, which limits our understanding of multi-decadal and -centennial spatial and temporal natural variability in this region.

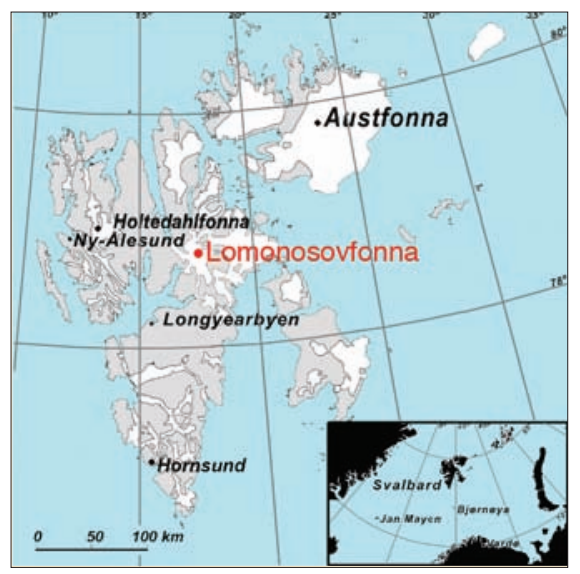

Figure 1: Drilling site at Lomonosovfonna, Svalbard.

In recent years, some high-resolution Arctic paleoclimate data have been obtained from ice cores (Figs. 1 and 2), and lake and ocean sediments. PAGES Working Group (WG) on Arctic climate during the last two millennia (Arctic2k) is a new initiative that will generate additional records and synthesize these high-resolution paleoclimate data to assess and elucidate both the tim- ing and variability of Arctic climate change during this period. In particular, the group will contribute to regional reconstructions of the last $2 \mathrm{kyr}$, under the new PAGES Focus 2 "Regional Climate Dynamics". Forty paleoclimatologists from both the data and modeling communities, gathered for the first Arctic2k workshop at NCAR, Boulder, USA on 8 March 2008, following the $38^{\text {th }}$ International Arctic Workshop at INSTAAR (5-7 March 2008).

During this one-day kick-off, workshop participants gave a preliminary overview of national and regional activities from the different paleocommunities. The future research issues for the Arctic 2k WG were discussed extensively. These included emphasizing the need to assess sensitivities and thresholds in the Arctic system, spatial and temporal modes of climate signals, persistence of anomalies, frequencies of extreme events, rates of change, and irreversibility and feedback mechanisms. Some central questions emerged:

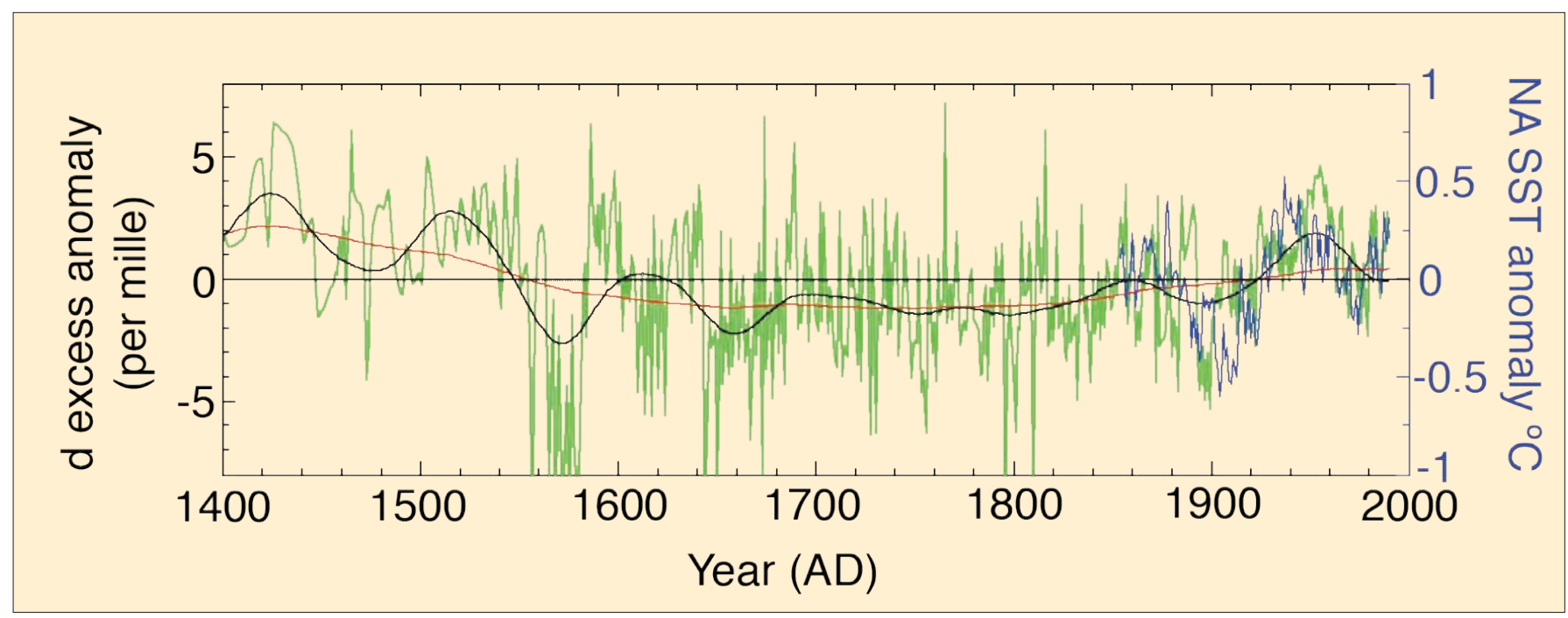

Figure 2: Left axis: Annual mean deuterium excess anomalies for the Lomonosovfonna ice core (green); non-linear trend (red) and non-linear trend with superimposed centennial component (black), both retrieved using Singular Spectrum Analysis. Deuterium excess $\left(d=\delta D-8^{*} \delta^{18} \mathrm{O}\right)$ is a sensitive indicator of sea surface temperature $(S S T)$ of the area where the precipitated moisture originally evaporated. Right axis: Annual mean SST anomalies in mid-latitude North Atlantic between $20^{\circ}$-45 $\mathrm{N}$ (blue) (Divine et al., submitted). 